\title{
Mianserin affects alarm reaction to conspecific chemical alarm cues in Nile tilapia
}

\author{
Rodrigo Egydio Barreto
}

Received: 8 January 2016/Accepted: 17 August 2016/Published online: 23 August 2016

(C) Springer Science+Business Media Dordrecht 2016

\begin{abstract}
In this study, I show that mianserin, a chemical with serotonin and adrenoceptor antagonist activities, increases fish vulnerability to a potential predator threat, when prey fish must deal with this threat based on conspecific chemical alarm cues. For that, I evaluated whether mianserin, diluted in the water, influences the behavioral responses of Nile tilapia (Oreochromis niloticus) to conspecific skin extract (chemical alarm cues). I found that, while mianserin did not abolished antipredator responses, this drug mitigates some components of this defensive reaction. Thus, a potential decrease in serotonin and adrenergic activities reduces the ability of dealing with predators when perceiving conspecific chemical alarm cues.
\end{abstract}

Keywords Chemical communication - Stress · Anxiety $\cdot$ Alarm substance $\cdot$ Mianserin

\section{Introduction}

In some fish species, putative chemical alarm substances (CAS) are thought to be produced and stored in

R. E. Barreto $(\square)$

Department of Physiology, CAUNESP, Institute of Biosciences of Botucatu, UNESP, Rubião Jr s/n, São Paulo 18618-970, Brazil

e-mail: rebarreto@yahoo.com the epidermal club cells and they are released when the epidermis is damaged, as in an injurious predator attack (Chivers and Smith 1998). In consequence, CAS induce antipredator behavior in conspecific fish, as documented for many fish species: speckled catfish (Pseudoplatystoma coruscans-Giaquinto and Volpato 2001; Barreto et al. 2012), convict cichlid (Amatitlania nigrofasciata-Alemadi and Wisenden 2002), zebrafish (Danio rerio-Speedie and Gerlai 2008; Gerlai 2010), Nile tilapia (Oreochromis niloticus-Barreto et al. 2010; Sanches et al. 2015), piauçu fish (Leporinus microcephalus-Barbosa-Junior et al. 2012), frillfin goby (Bathygobius soporator-Barreto et al. 2014), rainbow trout (Oncorhynchus mykissKopack et al. 2015) and several Pomacentridae coral reef fishes (Mitchell et al. 2012; Ramasamy et al. 2015).

Neurotransmitter activity modulates the defensive response to CAS. For instance, fluoxetine (a selective serotonin reuptake inhibitor drug) administration caused an anxiolytic-like effect in fish exposed to CAS, abolishing the antipredator response (see Barbosa-Junior et al. 2012). The psychiatric drug mianserin is a second-generation tetracyclic antidepressant and a potent serotonin (5-hydroxytryptamine [5-HT]) receptor (5-HT2 family) and $\alpha 2$-adrenoceptor antagonist. In fact, in fish, mianserin has biological effects: it causes endocrine disruption (van der Ven et al. 2006). These authors showed that mianserin has an estrogenic activity, disturbing the HypothalamoPituitary-Gonadal (HPG) axis. Regarding defensive 
reactions, there is no study on the effect of mianserin in fish. However, it is plausible to assume this potential effect in fish, since, in mammals, mianserin changes defensive behaviors (Griebel 1993; Griebel et al. 1997).

Based on these above-mentioned evidences, mianserin can be elected as a potential drug that could modulate fish antipredator behavior induced by CAS, due to changes in serotoninergic and adrenergic activities. In this study, operationally, I evaluated whether mianserin, diluted in the water, influences the behavioral responses of Nile tilapia (O. niloticus) to conspecific skin extract (CAS). This species was used as experimental model because it displays alarm reaction to CAS (Barreto et al. 2010; Sanches et al. 2015), hence, a suitable animal to test my hypothesis.

\section{Materials and methods}

Fish

The Nile tilapia (O. niloticus L.) (both sexes, $\sim 6.7 \mathrm{~cm}$-standard length and $\sim 10$ g—body mass) utilized here were a progeny reproduced in indoor tanks, whose the parental specimens were previously acquired from fishfarms. The tilapia were allocated in two stock tanks (total volume $=310 \mathrm{~L}$, water volume $=280 \mathrm{~L}$, holding density $=\sim 1.3 \mathrm{~g} / \mathrm{L}$ ). Stock tanks were equipped with biological-mechanical filters and had a continuous flow of water for constant water renewal. Water was kept in $\sim 26^{\circ} \mathrm{C}$, ammonia and nitrite about $<0.5 \mathrm{ppm}$ and $<0.05 \mathrm{ppm}$, respectively, and $\mathrm{pH}=\sim 7.0$. I set a light-dark cycle of $12 \mathrm{~h}: 12 \mathrm{~h}$, controlled by timer with abrupt transition from light to dark and vice versa. The illumination was provided by using artificial fluorescent lamps (daylight type) with about 120 lux at the tanks water surfaces. Fish were fed once a day with commercial fish pellets ( $32 \%$ of protein) in an amount of $\sim 5 \%$ of fish biomass. The leftover food and fish feces were sucked by the tank drainage system, avoiding organic matter accumulation.

\section{Experimental design}

My general experimental strategy consisted of $2 \times 2$ design. For that, mianserin solution or deionized water (drug-vehicle control) was administered by adding them into water of the experimental aquaria. After $24 \mathrm{~h}$ of exposure to mianserin or vehicle, I quantified the responses of fish to CAS (skin extract) or deionized water (extract eluent control) immediately after injection of these stimuli into the aquaria. For complete details of experimental schedule, see Fig. 1. In addition, a two-way ANOVA revealed no difference in fish length or weight among these four experimental conditions (see Table 1 for details).

As previously reported, Nile tilapia displays specific behavioral responses to chemical cues obtained from conspecific skin extract (Sanches et al. 2015), or even conspecific blood (Barreto et al. 2013), when compared to chemical stimuli from heterospecific fish that are phylogenetically distant from tilapia and are, therefore, unlikely to contain the same chemical alarm cues. Thus, a heterospecific chemical cue was not conducted here as control stimulus, because tilapia responses are specific to conspecific cues and not a general response to any new scent.

Forty tilapias ( $n=10$ for each condition) from the stock population were randomly selected and housed in individual glass aquaria $(40 \times 23 \times 25 \mathrm{~cm}$; $1 \mathrm{fish} /$ aquarium). The fish were acclimated to the conditions of the experimental aquaria for 10 days. The fish were fed daily as described above, and the leftover food was removed. After this period, fish antipredator behavior was recorded for $5 \mathrm{~min}$ before chemical stimulus (baseline). Next, a chemical stimulus was injected into the experimental aquaria, and fish antipredator behavior was recorded $10 \mathrm{~s}$ later for an additional $5 \mathrm{~min}$ (post-stimulus period). A methylene blue dye test demonstrated that the colorant was completely spread throughout the aquarium in $\sim 8 \mathrm{~s}$. Behavior recording occurred from 11 to $14 \mathrm{~h}$ in a random order defined by raffle. During this interval, the plasma level of cortisol in Nile tilapia, a factor that affects alarm reaction when increased (Barreto et al. 2014), is low and it peaks during the early photophase ( $\sim 06 \mathrm{~h}$ ) (Nikaido et al. 2010).

\section{Mianserin}

I administered mianserin hydrochloride (CAS number: 21535-47- 7) purchased from Tocris Bioscience (Ellisville, MO, USA). The drug was applied noninvasively by adding them directly into the water of the experimental aquaria. For drug application, $5 \mathrm{mg}$ of mianserin was diluted into $50 \mathrm{~mL}$ of distilled water 
Fig. 1 Experimental schedule

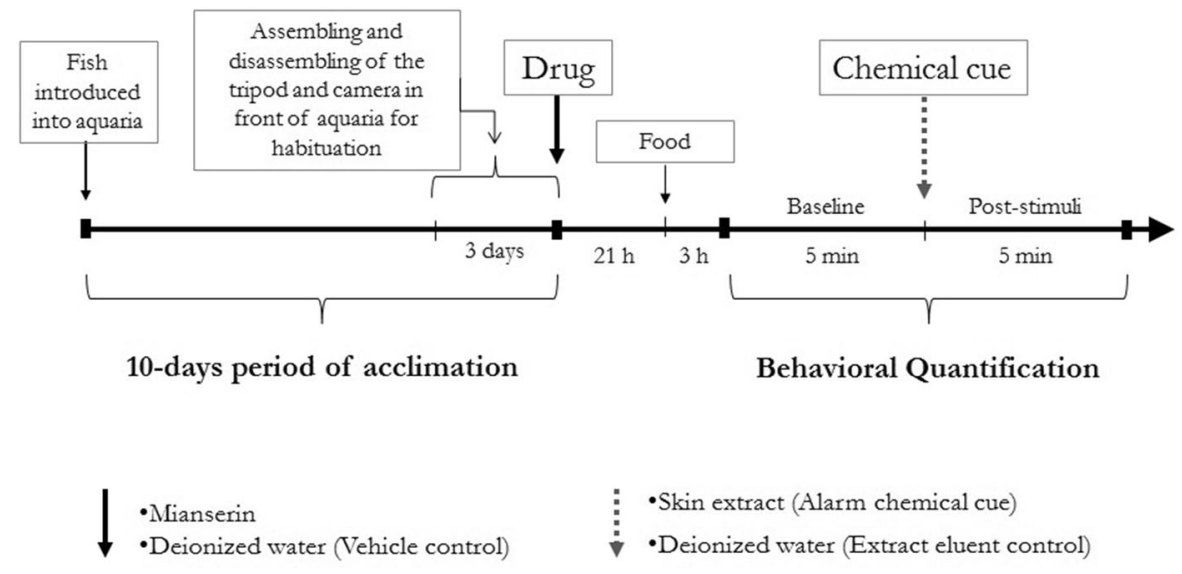

Table 1 Mean ( $\pm \mathrm{SD} ; n=10$ ) standard length and body mass of Nile tilapia $O$. niloticus according to experimental conditions

\begin{tabular}{lllr}
\hline Drugs & Chemical stimuli & \multicolumn{2}{l}{ Biometric variable } \\
\cline { 3 - 4 } & & Length $(\mathrm{cm})$ & \multicolumn{1}{c}{ Mass $(\mathrm{g})$} \\
\hline Vehicle & Extract eluent & $6.7 \pm 0.3$ & $10.1 \pm 1.4$ \\
& Skin extract & $6.7 \pm 0.2$ & $9.8 \pm 1.7$ \\
Mianserin & Extract eluent & $6.6 \pm 0.2$ & $9.6 \pm 1.4$ \\
& Skin extract & $6.7 \pm 0.3$ & $10.0 \pm 1.6$ \\
\hline
\end{tabular}

Both length and weight of fish were considered normally distributed and homoscedastic according to KolmogorovSmirnov test and Cochran's C test, respectively. Thus, parametric statistics were conducted and I found no significant difference for these biometric variables among experimental conditions as revealed by two-way ANOVA (lower $P$ value was $p>0.405$ ). Deionized water was either drug vehicle or extract eluent

and $5 \mathrm{~mL}$ of this solution was injected into the aquaria water (total water volume $=20 \mathrm{~L}$ ). Thus, the concentration reached was $5 \mu \mathrm{g}$ of mianserin/L of aquarium water. Mianserin can cause endocrine disruption at low concentration in water $(25 \mu \mathrm{g} / \mathrm{L})$ in zebrafish (van der Ven et al. 2006). Here, to investigate the potential adverse effects of and mode of action by aquatic exposure to mianserin in fish behavior, I sought to assess a concentration lower than the successfully used by van der Ven et al. (2006). In addition, zebrafish acutely exposed to fluoxetine diluted in water $(1 \mu \mathrm{g} / \mathrm{L})$, a substance that also interferes with serotonin activity, have changes in stress responses (Abreu et al. 2014). This concentration was also utilized herein as a parameter for conducted my procedures.
Chemical cues

The skin extract was prepared based on Brown et al. (2004). For this, I used three tilapias coming from the same stock tanks as those fish used in this experiment. The fish were sacrificed by spinal cord section without the use of anesthetics to avoid chemical interference. Then the fish skin was carefully removed, delimiting a trapezoidal area on both sides with the aid of a tweezer and a scalpel, and immediately placed into $50 \mathrm{~mL}$ of deionized water. The skin was homogenized and then filtered using glass wool placed in a glass funnel to remove the remaining fragments of tissue. The final volume was adjusted with addition of deionized water, and the final 'concentration' of tilapia skin extract was $2.6 \mathrm{~mm}^{2}$ of skin $/ \mathrm{mL}$ of deionized water (Barreto et al. 2010). I placed extracts into beakers and kept them chilled by using frozen gel packs inside a Styrofoam box for immediate use during the trial. The eluent of the extracts, used as a chemical stimulus control, was kept under identical conditions. A volume of $5 \mathrm{~mL}$ of skin extract or eluent was applied to tests aquaria using a syringe and during this procedure fish could not see the investigator (Sanches et al. 2015). The chemical stimuli were injected at the water surface just above the bubbles produced by the air compressor to facilitate dispersion.

Fish behavior

The behavior was quantified by analyzing the videos without knowing which treatment each fish had been submitted. As indicators of antipredator responses, I quantified the swimming activity, the time spent near the tank bottom, the frequency of bristling of the 
dorsal fin, the frequency of dashes and the frequency and duration of episodes of freezing.

To assess the swimming activity, I put a grid design on the back wall of the aquarium that had nine identical quadrants and quantified the frequency of quadrants changes (Barreto et al. 2010; Miyai et al. 2016). The presence of an animal in one quadrant was scored considering the bigger part of a fish body that was inside a quadrant. When it was not evident, I kept as reference point the head region. The evaluation of the presence of fish in quadrants over time allowed us to estimate the percentage of time fish spent in each of part of the aquarium (near surface or near bottom or in the middle of water column). I also considered here the time spent near the bottom, as it is a fish defensive response (Speedie and Gerlai 2008).

The Nile tilapia has spines in the dorsal fin. In context of confrontation, when paired with a conspecific competitor (Barki and Volpato 1998) or a predator (Freitas and Volpato 2008), they tend to keep dorsal fin bristled, consequently, dorsal spines as well. The frequency of bristling of the dorsal fin (FBDF) was binary quantified. When the position of the fin was completely bristled, I scored one (1), on the contrary zero (0). It was done every $10 \mathrm{~s}$ during the two intervals of $5 \mathrm{~min}$ of observation (before and after injection of chemical stimuli), totaling 30 observations in each period. If the dorsal fin was only partially bristle, I scored zero (0), because in this position, the spine does not form an angle (ideal angle $=\sim 90^{\circ}$ considering the longitudinal body axis of tilapia) that could act as a defense weapon in the advent of predator bite.

A fast swimming in an escape route is considered a defensive maneuver, but in an aquarium that is not possible. However, we can see rapid and unplanned swim (dashing) from one side to another and from the bottom to the surface and vice versa (Giaquinto and Volpato 2001). Here, I also quantified the frequency of dashes as a defensive reaction.

Another defensive response in fish exposed to alarm substance is a freezing reaction (Lawrence and Smith 1989). I considered an animal was freezing when it is directed to the tank bottom, touching the gravel and the vertical wall of the aquarium (but generally they went to aquaria corners), and stood still, with little or no movement of the dorsal and caudal fins (Lawrence and Smith 1989). I recorded both frequency and duration of freezing episodes.
Statistical analyses

Normality and homoscedasticity were assessed by utilizing Kolmogorov-Smirnov test and Cochran's C test, respectively. The data of time at the bottom and FBDF reached these premises. The data of frequency and duration of freezing episodes and frequency of dashes achieved these premises only after log-transformation of the values [transformed value $=\log 10$ $($ value +2$)$ ]. In the case of swimming activity, data were considered neither normally distributed nor homoscedastic even after square root or log-transformation. However, I reached these premises by subtracting baseline from post-stimulus values of each individual ( $\Delta=$ post-stimulus-baseline). The data of swimming activity, freezing frequency and duration, and frequency of dashes were analyzed by two-way ANOVA, having drugs (mianserin or vehicle) and chemical cues (skin extract or extract eluent) as independent categorical factors. For time spend near the tank bottom and FBDF, I had the same categorical factors, but data were compared by a three-way mixed ANOVA, once I included time (baseline or poststimuli-after chemical cues exposure) as repeated measure. When necessary ANOVAs were complemented by post-hoc test of Duncan. Significant statistical differences were considered when $p<0.05$.

Animal welfare statement

This study complied with the Ethical Principles in Animal Research adopted by the Brazilian College of Animal Experimentation (COBEA) and was approved by the School of Medicine of Ribeirão Preto of the University of São Paulo Ethics Committee on Animal Research (CETEA), Protocol No. 010/2006.

\section{Results}

Swimming activity

I found a significant effect of chemical cues on swimming activity $\left(F_{(1 ; 36)}=6.54 ; p=0.0149\right)$, but no effect of the $\operatorname{drug}\left(F_{(1 ; 36)}=0.25 ; p=0.62\right)$ or interaction between these factors $\left(F_{(1 ; 36)}=0.005 .54\right.$; $p=0.94)$. This finding denotes that skin extract induced swimming activity to decrease compared to fish exposed to extract eluent (Fig. 2). 
Time spent near the aquaria bottom

I found no significant effect of drugs, chemical cues or time on the time at the bottom (Fig. 3a). In addition, no significant interaction among these variable was also revealed by ANOVA (Fig. 3b).

The frequency of bristling of the dorsal fin

I found no significant effect of drugs, chemical cues or time on FBDF and also no significant interaction among them (Fig. 3b). However, I conducted an extra analysis considering the fish that received vehicle and were exposed to skin extract by using Wilcoxon matched pairs test. This test revealed a significant increase in FBDF $(Z=2.20 ; p=0.0277)$ induced by skin extract (Fig. 3b).

Frequency and duration of freezing episodes

I found a significant effect of chemical cues for both frequency $\left(F_{(1 ; 36)}=12.79 ; p=0.0010 ;\right.$ Fig. $\left.4 \mathrm{a}\right)$ and duration $\left(F_{(1 ; 36)}=13.36 ; p=0.0008\right.$; Fig. $\left.4 \mathrm{~b}\right)$ of freezing episodes. For both variables, an increased level was observed in response to skin extract compared to extract eluent, independently of the drug that fish were exposed.

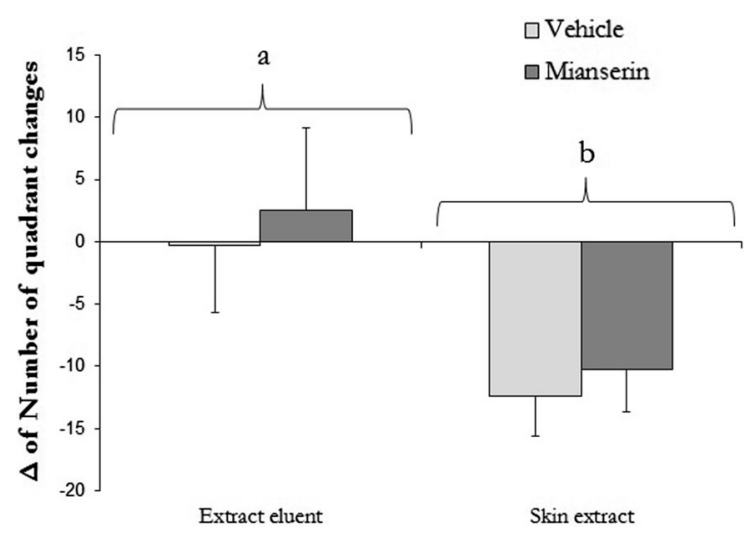

Fig. 2 Mean $( \pm \mathrm{SD} ; n=10)$ of changes in swimming activity of Nile tilapia $O$. niloticus treated with mianserin or vehicle and exposed to chemical alarm cue or eluent. A two-way ANOVA revealed a significant effect of chemical cues on swimming activity $\left(F_{(1 ; 36)}=6.54 ; p=0.0149\right)$, but no effect of the drug $\left(F_{(1 ; 36)}=0.25 ; p=0.62\right)$ or interaction between these factors $\left(F_{(1 ; 36)}=0.005 .54 ; p=0.94\right)$. Different letters denote a statistical significant difference
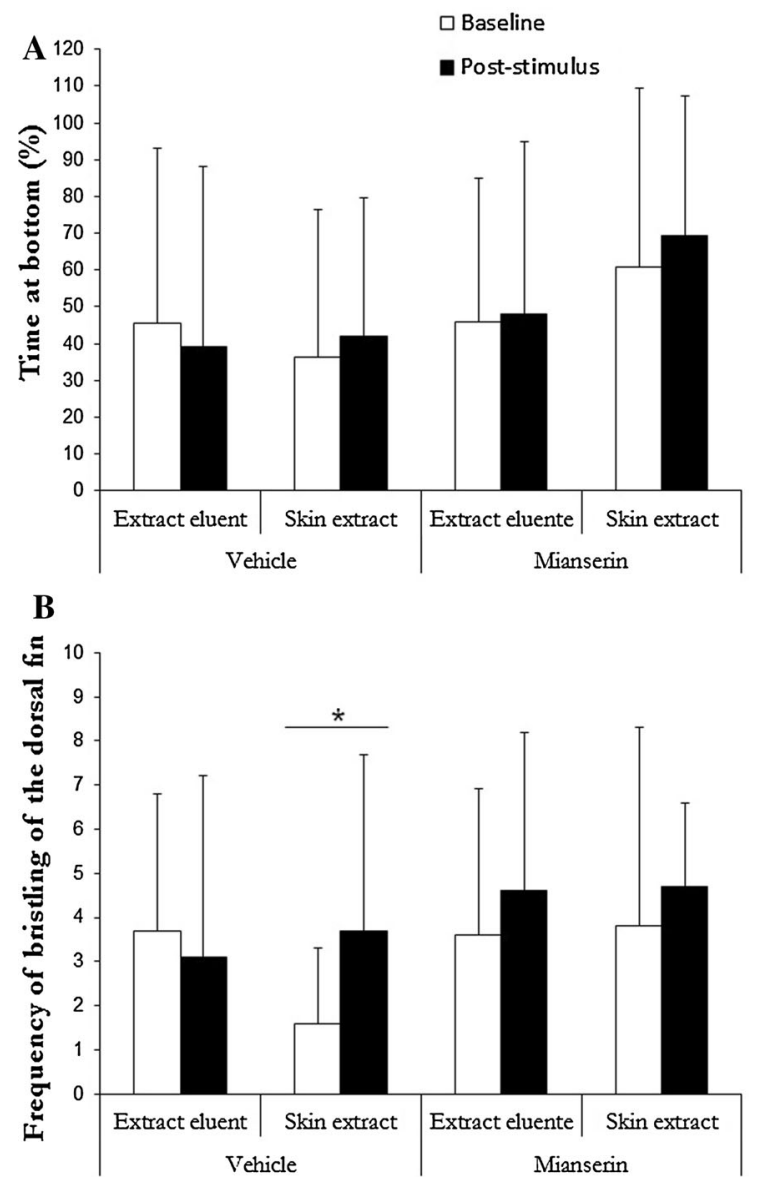

Fig. 3 Mean $( \pm \mathrm{SD} ; n=10)$ time at the bottom (a) and FBDF (b) of Nile tilapia $O$. niloticus treated with mianserin or vehicle and exposed to chemical alarm cue or eluent. A three-way mixed ANOVA showed no significant effect of drugs, chemical cues, time or interactions between these factors on the time at the bottom and FBDF. An extra analysis considering the fish that received vehicle and were exposed to skin extract revealed a significant increase $(*)$ in FBDF (Wilcoxon matched pairs test; $Z=2.20 ; p=0.0277)$ induced by chemical alarm cue $(\mathbf{b})$

Frequency of dashes

The most important result was observed for dashing response. I found a significant interaction between drugs and chemical cues $\left(F_{(1 ; 36)}=4.55 ; p=0.0399\right.$; Fig. 5). Fish exposed to skin extract displayed a higher frequency of dashes than those exposed to extract eluent, but this effect was weaker for fish treated with mianserin, indicating that this drug mitigates dashing in the Nile tilapia. 

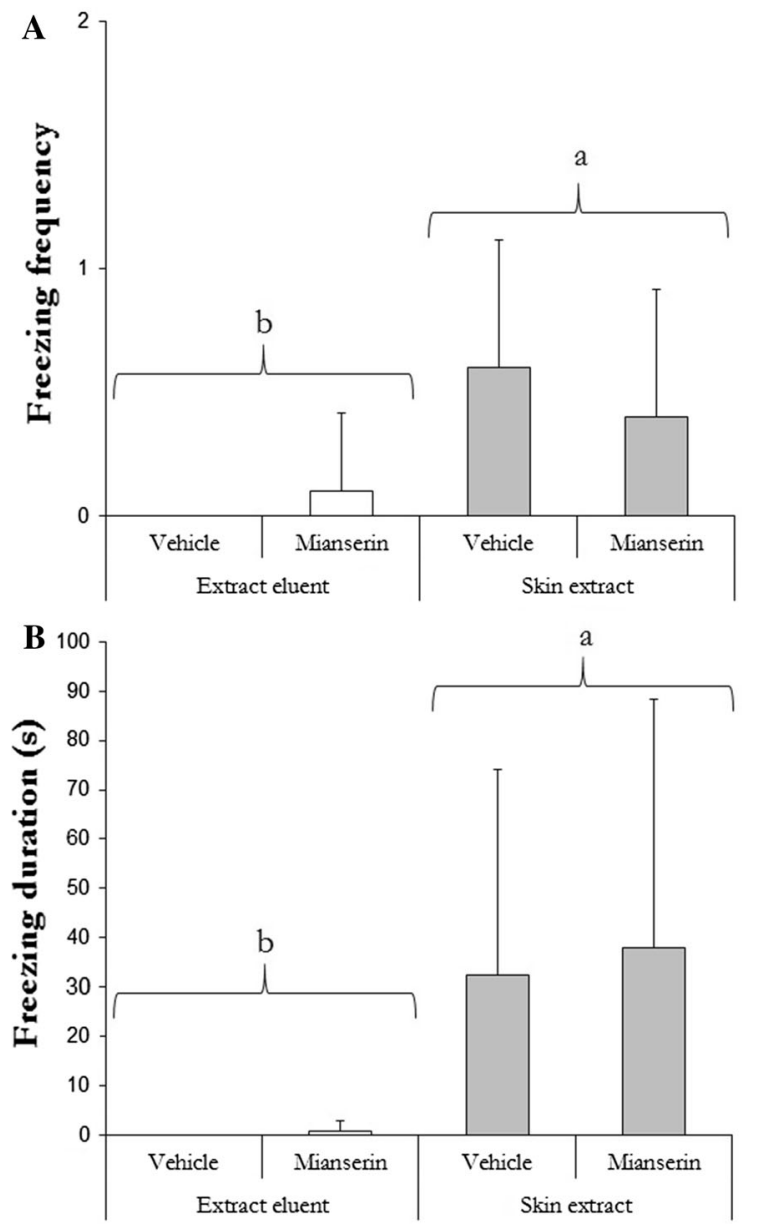

Fig. 4 Mean ( $\pm \mathrm{SD} ; n=10)$ of freezing frequency (a) or duration (b) of Nile tilapia $O$. niloticus treated with mianserin or vehicle and exposed to chemical alarm cue or eluent. A significant effect of chemical cues for both frequency $\left(F_{(1 ; 36)}=12.79 ; \quad p=0.0010 ; \quad\right.$ a) and duration $\left(\mathrm{F}_{(1 ; 36)}=13.36 ; p=0.0008 ; \mathbf{b}\right)$ of freezing episodes was showed by two-way ANOVA. For both variables, an increased level was observed in response to skin extract compared to extract eluent, independently of the drug (mianserin or vehicle) that fish were exposed. Different letters denote a statistical significant difference

\section{Discussion}

The administration of mianserin modified the expression of alarm reaction to conspecific alarm substance (CAS) in the Nile tilapia. Fish exposed to mianserin still present decreased activity and freezing reaction in response to CAS. They decreased, however, the expression of dashing and were not prompt to increase the bristling of dorsal fin spines. A modification in fish antipredator behavior can consequently influence fish

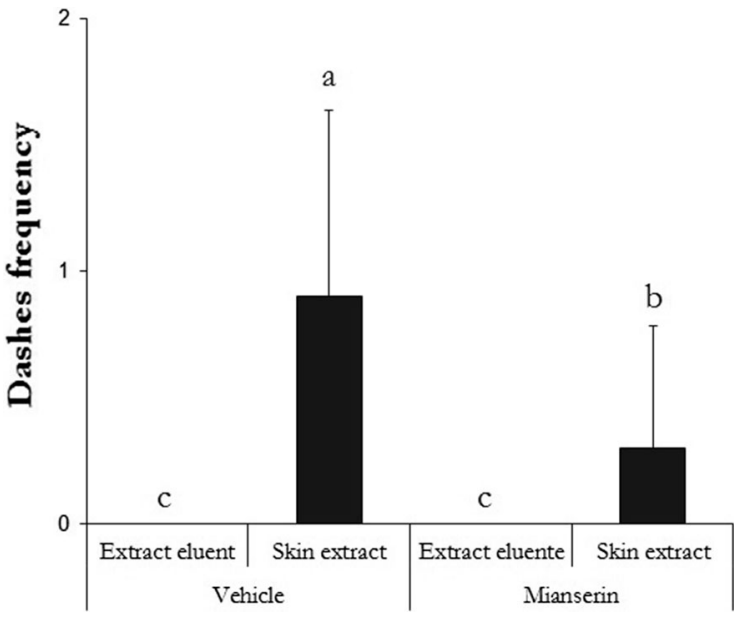

Fig. 5 Mean $( \pm \mathrm{SD} ; n=10)$ of dashes frequency of Nile tilapia $O$. niloticus treated with mianserin or vehicle and exposed to chemical alarm cue or eluent. A significant interaction between drugs and chemical cues $\left(F_{(1 ; 36)}=4.55\right.$; $p=0.0399$ ) was revealed by two-way ANOVA. Fish exposed to skin extract displayed a higher frequency of dashes than those exposed to extract eluent, but this effect was weaker for fish treated with mianserin, indicating that this drug mitigates dashing in the Nile tilapia. Different letters denote a statistical significant difference

ability to deal with threats arising from potential predators. Thus, a potential decrease in serotonin and adrenergic activity, due to mianserin effects, decrease the ability of dealing with predators when perceiving the CAS. Mianserin is a potent serotonin-5-HT receptors (mainly 5-HT2A and 5-HT2C) - and $\alpha 2-$ adrenoceptor antagonist. The 5-HT2A and 5-HT2C receptors have been identified in fish brain (Norton et al. 2008; Schneider et al. 2012), including the diencephalon, where hypothalamus is located (Mager et al. 2012). The hypothalamus is a brain structure linked to defensive reactions in fish (Winberg et al. 1993; Wolkers et al. 2015). The $\alpha 2$-adrenoceptors are G-protein-coupled receptors and are found in fish brain, mediating many of the physiological effects of norepinephrine and epinephrine (Ruuskanen et al. 2005), a system linked to defensive reactions ('fight or flight') (Perry and Bernier 1999). Based on these initial evidences, future studies must address the effects of more specific drugs to continue to elucidate the neural mechanisms underlying the alarm reaction to CAS in fish and potential influences of environmental presence of psychoactive drugs.

The administration of mianserin did not abolish the ability of fish to display a decrease in swimming 
activity by exposure to CAS. The freezing component of antipredator behavior was also not abolished or decreased in the tilapia, and it occurred at the same magnitude (duration) of fish untreated with mianserin. Thus, mianserin-treated fish still display defensive reaction when detecting CAS. However, other components of antipredator behavior were modified and can negatively affect the way tilapia must deal with predators. In this context, they had a decreasing in dashing frequency, a response related to escape maneuvers. This finding suggests that fish exposed to mianserin have a reduced capability to flee. In addition, I only detected an increase in bristling of the dorsal fin spines in fish exposed to vehicle and alarm substance. Fin bristling is a way of positioning tilapia weaponry in an angle $\left(\sim 90^{\circ}\right)$ that could hurt a predator's mouth when it is biting a tilapia, allowing them to escape (Freitas and Volpato 2008). Therefore, mianserin-treated fish did not show an anticipatory properly positioning of their weaponry for a potential use.

The physiological state of a fish can affect alarm response (Giaquinto and Volpato 2001; BarbosaJunior et al. 2012; Barreto et al. 2014) and potentially influence ecological processes linked to food webs, because the characters related to foraging and feeding are crucial to these processes. Among them, the use of predatory signals to detect and respond to them appropriately has strong relevance for prey survival. The movement of the prey is used as a key stimulus for numerous types of predators to orient their first contact with the prey (Lima and Dill 1990; Burrows 1994; Burrows and Gibson 1995). Therefore, reducing the activity and/or displaying freezing can be considered a way to reduce the susceptibility of the prey to be detected by predators (Houtman and Dill 1994; Gyssels and Stoks 2005). We can consider, therefore, that a factor that induces decreased activity and/or increases the frequency and/or duration of freezings improves the survival probability of a prey. As an example, frillfin goby B. soporator treated with cortisol increase immobility and the strategy of refuging in burrows in response to CAS (Barreto et al. 2014). In this context, cortisol appears to induce an adaptive response to potentially increase prey capability of defense. In this study, fish were able to decrease their activity in response to CAS, as well as, were capable of exhibiting freezing. However, mianserin did not improve these components of the antipredator behavior, because they just were not abolished. In this context, there is a cost-benefit relationship of remaining immobile (or less active) or fleeing. In fact, the latency to escape after immobility decreases as the probability of success of a predator attack increases (Martin et al. 2009). The display of fast swimming in an escape route (dashing) is required to evade an unavoidable attack of a predator. As mianserin decreased the expression of dashings and there was not an increase in dorsal fin bristling exposing the spines, which could be an effective defense to an inevitable bite of a predator, I conclude that this drug increases the fish vulnerability to a predator attack.

As shown herein, mianserin can affect fish response to CAS; hence, future investigations must address potential effect of this drug in trace levels, in order to elucidate whether the environmental concentrations of mianserin could represent an environmental problem, as have been shown for other drugs (Brodin et al. 2013). In fact, mianserin has been found in trace levels in aquatic environment: in sewage effluents tested in Sweden was present at a concentration in the order of $10 \mathrm{ng} / \mathrm{L}$ (Fick et al. 2010) and one of $0.9 \mathrm{ng} / \mathrm{L}$ was detected in rivers in Poland (Giebultowicz and NaleczJawecki 2014). In addition, a Europe-wide study identified average concentration of mianserin in wastewater effluents to be $1.5 \mathrm{ng} / \mathrm{L}$ (European Union, 2012 - http://publications.jrc.ec.europa.eu/repository/ bitstream/JRC76400/lb-na-25563-en.pdf). This effect might be still potentially worse, because some psychoactive drugs diluted in the water (such as diazepam, fluoxetine, risperidone and buspirone) were found to be attractive to the fish (Abreu et al. 2016) and, in light of that fact, fish could exposed oneself in areas with chemicals that would change negatively its behavior.

Acknowledgments I am thankful for technical assistance of Mr. A. C. B. Tardivo. This study was financially supported by the Fundação para o Desenvolvimento da UNESPFUNDUNESP (Process 00017/08).

\section{References}

Abreu MS, Koakoski G, Ferreira D, Oliveira TA, Rosa JGS, Gusso D et al (2014) Diazepam and fluoxetine decrease the stress response in zebrafish. PLoS ONE 9:e103232. doi:10. 1371/journal.pone.0103232 
Abreu MS, Giacomini ACV, Gusso D, Rosa JGS, Koakoski G, Kalichaka F, Idalêncio R, Oliveira TA, Barcellos HHA, Bonan CD, Barcellos LJG (2016) Acute exposure to waterborne psychoactive drugs attract zebrafish. Comp Biochem Physiol Part C Toxicol Pharmacol 179:37-43. doi:10.1016/j.cbpc.2015.08.009

Alemadi SD, Wisenden BD (2002) Antipredator response to injury-released chemical alarm cues by convict cichlid young before and after independence from parental protection. Behaviour 139:603-611

Barbosa-Junior A, Alves FL, Pereira ADF, Ide LM, Hoffmann A (2012) Behavioral characterization of the alarm reaction and anxiolytic-like effect of acute treatment with fluoxetine in piaucu fish. Physiol Behav 105:784-790

Barki A, Volpato GL (1998) Early social environment and the fighting behaviour of young O. niloticus (Pisces, Cichlidae). Behaviour 135:913-929

Barreto RE, Barbosa A, Giassi ACC, Hoffmann A (2010) The club cell and behavioural and physiological responses to chemical alarm cues in the Nile tilapia. Mar Freshw Behav Physiol 43:75-81

Barreto RE, Barbosa A, Hoffmann A (2012) Ventilatory responses to skin extract in catfish. Aquat Biol 15:205-214

Barreto RE, Miyai CA, Sanches FHC, Giaquinto PC, Delicio HC, Volpato GL (2013) Blood cues induce antipredator behavior in Nile tilapia conspecifics. PLoS ONE 8:e54642. doi:10.1371/journal.pone.0054642

Barreto RE, Barbosa-Junior A, Urbinati EC, Hoffmann A (2014) Cortisol influences the antipredator behavior induced by chemical alarm cues in the Frillfin goby. Horm Behav 65:394-400. doi:10.1016/j.yhbeh.2014.03.007

Brodin T, Fick J, Jonsson M, Klaminder J (2013) Dilute concentrations of a psychiatric drug alter behavior of fish from natural populations. Science 339:814-815. doi:10.1126/ science. 1226850

Brown GE, Foam PE, Cowell HE, Fiore PG, Chivers DP (2004) Production of chemical alarm cues in convict cichlids: the effects of diet, body condition and ontogeny. Ann Zool Fenn 41:487-499

Burrows MT (1994) An optimal foraging and migration model for juvenile plaice. Evol Ecol 8:125-149

Burrows MT, Gibson RN (1995) The effects of food, predation risk and endogenous rhythmicity on the behavior of juvenile plaice, Pleuronectes platessa L. Anim Behav 50:41-52

Chivers DP, Smith RJF (1998) Chemical alarm signalling in aquatic predator-prey systems: a review and prospectus. Ecoscience 5:338-352

Fick J, Lindberg RH, Parkkonen J, Arvidsson B, Tysklind M, Larsson DGJ (2010) Therapeutic levels of levonorgestrel detected in blood plasma of fish: results from screening rainbow trout exposed to treated sewage effluents. Environ Sci Technol 44:2661-2666

Freitas RHA, Volpato GL (2008) Behavioral response of Nile tilapia to an allopatric predator. Mar Freshw Behav Physiol 41:267-272

Gerlai R (2010) Zebrafish antipredatory responses: a future for translational research? Behav Brain Res 207:223-231

Giaquinto PC, Volpato GL (2001) Hunger suppresses the onset and the freezing component of the antipredator response to conspecific skin extract in pintado catfish. Behaviour 138:1205-1214

Giebultowicz J, Nalecz-Jawecki G (2014) Occurrence of antidepressant residues in the sewage-impacted Vistula and Utrata rivers and in tap water in Warsaw (Poland). Ecotoxicol Environ Saf 104:103-109

Griebel G (1993) Système sérotoninergique et réactivité émotionnelle chez le rat et chez la souris. Approche pharmacologique. Univ Louis Pasteur, Strasbourg

Griebel G, Rodgers RJ, Perrault G, Sanger DJ (1997) Risk assessment behaviour: evaluation of utility in the study of 5-HT-related drugs in the rat elevated plus-maze test. Pharmacol Biochem Behav 57:817-827

Gyssels FGM, Stoks R (2005) Threat-sensitive responses to predator attacks in a damselfly. Ethology 111:411-423

Houtman R, Dill LM (1994) The influence of substrate color on the alarm response of tidepool sculpins (Oligocottus maculosus, Pisces, Cottidae). Ethology 96:147-154

Kopack CJ, Broder ED, Lepak JM, Fetherman ER, Angeloni LM (2015) Behavioral responses of a highly domesticated, predator naive rainbow trout to chemical cues of predation. Fish Res 169:1-7

Lawrence BJ, Smith RJF (1989) Behavioral response of solitary fathead minnows, Pimephales promelas, to alarm substance. J Chem Ecol 15:209-218

Lima SL, Dill LM (1990) Behavioural decisions made under the risk of predation: a review and prospectus. Can J Zool 68:610-640

Mager EM, Medeiros LR, Lange AP, McDonald MD (2012) The toadfish serotonin 2A (5-HT(2A)) receptor: molecular characterization and its potential role in urea excretion. Comp Biochem Physiol A Mol Integr Physiol 163:319-326. doi:10.1016/j.cbpa.2012.07.013

Martin J, Luque-Larena JJ, López P (2009) When to run from an ambush predator: balancing crypsis benefits with costs of fleeing in lizards. Anim Behav 78:1011-1018

Mitchell MD, Cowman PF, McCormick MI (2012) Chemical alarm cues are conserved within the coral reef fish family pomacentridae. PLoS ONE 7:e47428. doi:10.1371/journal. pone. 0047428

Miyai CA, Sanches FHC, Pinho-Neto CF, Barreto RE (2016) Effects of predator odour on antipredator responses of Nile tilapia. Physiol Behav 165:22-27. doi:10.1016/j.physbeh. 2016.06.033

Nikaido Y, Aluru N, McGuire A, Park YJ, Vijayan MM, Takemura A (2010) Effect of cortisol on melatonin production by the pineal organ of tilapia, O. mossambicus. Comp Biochem Physiol A: Mol Integr Physiol 155:84-90

Norton WH, Folchert A, Bally-Cuif L (2008) Comparative analysis of serotonin receptor (HTR1A/HTR1B families) and transporter (slc6a4a/b) gene expression in the zebrafish brain. J Comp Neurol 511:521-542

Perry SF, Bernier NJ (1999) The acute humoral adrenergic stress response in fish: facts and fiction. Aquaculture 177:285-295

Ramasamy RA, Allan BJM, McCormick MI (2015) Plasticity of escape responses: prior predator experience enhances escape performance in a coral reef fish. PLoS ONE 10:e0132790. doi:10.1371/journal.pone.0132790

Ruuskanen JO, Peitsaro N, Kaslin JV, Panula P, Scheinin M (2005) Expression and function of alpha-adrenoceptors in 
zebrafish: drug effects, mRNA and receptor distributions. J Neurochem 94:1559-1569

Sanches FHC, Miyai CA, Pinho-Neto CF, Barreto RE (2015) Stress responses to chemical alarm cues in Nile tilapia. Physiol Behav 149:8-13. doi:10.1016/j.physbeh.2015.05. 010

Schneider H, Fritzky L, Williams J, Heumann C, Yochum M, Pattar K, Noppert G, Mock V, Hawley E (2012) Cloning and expression of a zebrafish 5-HT(2C) receptor gene. Gene 502:108-117. doi:10.1016/j.gene.2012.03.070

Speedie N, Gerlai R (2008) Alarm substance induced behavioral responses in zebrafish (D. rerio). Behav Brain Res 188:168-177 van der Ven K, Keil D, Moens LN, Van Leemput K, Van Remortelt P, De Coen WM (2006) Neuropharmaceuticals in the environment: mianserin-induced neuroendocrine disruption in zebrafish (D. rerio) using cDNA microarrays. Environ Toxicol Chem 25:2645-2652. doi:10.1897/05495R.1

Winberg S, Myrberg AA Jr, Nilsson GE (1993) Predator exposure alters brain serotonin metabolism in bicolour damselfish. NeuroReport 4:399-402

Wolkers CP, Serra M, Urbinati EC (2015) Social challenge increases cortisol and hypothalamic monoamine levels in matrinxã (Brycon amazonicus). Fish Physiol Biochem 41:1501-1508. doi:10.1007/s10695-015-0102-5 